\title{
Measurement and Modelling of Moisture Sorption Isotherm and Heat of Sorption of Fresh Feces
}

\author{
Claire Remington ${ }^{1} \mathbb{D}$, Catherine Bourgault ${ }^{2}$ and Caetano C. Dorea ${ }^{1, * \mathbb{C}}$ \\ 1 Department of Civil Engineering, University of Victoria, Victoria, BC V8P 5C2, Canada; cremington@uvic.ca \\ 2 Centre for Affordable Water and Sanitation Technology, Calgary Alberta, AB T2H 2L8, Canada; \\ cbourgault@cawst.org \\ * Correspondence: caetanodorea@uvic.ca
}

Received: 31 December 2019; Accepted: 19 January 2020; Published: 22 January 2020

\begin{abstract}
The drying (or dewatering) of fresh feces and fecal sludge is a productive step in the management of sanitation, waste treatment, and resource recovery services. An improved understanding of fresh feces and fecal sludge drying would contribute to the development and deployment of fecal sludge management services. However, there is a lack of available literature on the fundamental drying characteristics of fresh feces. In response to this gap, this work shares experimental results for equilibrium moisture content of fresh feces at different water activity levels $\left(a_{w}\right)$ and proposes the use of the Guggenheim, Anderson, and de Boer (GAB) model for predicting $a_{w}$, calculating the heat of sorption, and estimating the corresponding energy requirements for drying of fresh feces. This is the first time this work has been done with fresh feces. The total heat of evaporation was significant up to a moisture content of about $0.2 \mathrm{~kg}$ water per $\mathrm{kg}$ dry solids. In addition to informing drying process design, the sorption isotherm can be used to predict microbial activity, which could improve the management of feces and fecal sludge from a public health perspective. These data in turn will be used to promote access to dignified, safe, and sustainable sanitation.
\end{abstract}

Keywords: desiccation; drying; fecal sludge; fresh feces; heat of sorption; moisture sorption isotherms; sanitation

\section{Introduction}

Effective sanitation, waste treatment and resource recovery systems are central when it comes to the protection of human health, prevention of environmental degradation, and reclamation of valuable resources. An estimated $61 \%$ of the global population, or 4.6 billion people, is without access to household-level sanitation and waste treatment in which excreta is contained and treated [1]. Excreta that is unsafely managed can leach into the environment, polluting surface water and groundwater. This has significant public health consequences: about $88 \%$ of all diarrheal deaths are attributed to inadequate water, sanitation, and hygiene (WaSH) systems and diarrheal disease caused over 71 million disability-adjusted life years (DALYs) lost in 2010 [2,3]. This global sanitation crisis is "rooted in aspects of poverty, power, and inequality" [4]. Prioritizing universal access to effective sanitation systems is an issue of equity with far-reaching implications: the poorest households are least able to invest in their own sanitation systems and are the most vulnerable to adverse public health, and consequently socioeconomic, outcomes associated with ineffective sanitation systems [5].

Drying is a complex, multi-equilibrium process, and numerous models with varying degrees of sophistication have been developed to simulate the process. Models are used to inform and optimize design and control of process conditions [6-8]. There has been initial research on fecal sludge drying, including calculating the energy requirements for dewatering pit latrine sludge to determine the overall energy balance associated with the production of solid fuel char briquettes from excreta [9]. Drying 
is a crucial step in any thermal treatment process. It has been estimated that more than $95 \%$ of the energy required to produce char from feces is used in drying feces [10] and $50 \%$ of the heat required from fuel could be sufficient for all pre-drying, drying, and pyrolysis steps [11]. Drying is driven by the difference between the thermodynamic activity of water as vapor in the atmosphere and water as moisture in the wet solid. However, there is no published literature for three key thermodynamic characteristics-moisture sorption isotherms (MSI), heat of sorption, and energy requirements for drying — or a widely-accepted model that estimates these parameters for fresh feces.

MSIs are a graphical representation showing the evolution of the moisture content within a specific material vs. water activity $\left(a_{w}\right)$ [12]. The parameter $a_{w}$ is equated to relative humidity when relative humidity is fixed within the atmosphere; it is defined as the ratio of a material's vapor pressure to distilled water vapor pressure under the same temperature and humidity conditions [13]. Water activity is a thermodynamic property used to describe the availability of water within a material. Sorption isotherms describe the change in a sample's moisture content in relation to the thermodynamic activity of the water at a fixed temperature [14]. The relationship between moisture content and $\mathrm{a}_{\mathrm{w}}$ is determined by chemical composition, or by the availability of polar sites for the binding of water molecules [13]. The moisture content and chemical composition of fresh feces varies with factors like vegetarian vs. non-vegetarian diet, fiber content of diet, age, and health conditions [15]. MSIs are used to calculate the isoteric heat of sorption for estimates of drying times and energy requirements.

An improved understanding of the thermodynamic properties of fresh feces drying has important ramifications. Water activity describes the degree to which moisture is bound within a solid and subsequently its availability to participate in physical, chemical, and microbiological reactions [16]. Understanding water activity and the thermodynamic properties of fresh feces and fecal sludge are important in the design and optimization of drying operations based on a rational understanding of the food-solid interactions [16]. Drying is an important treatment mechanism from both a public health and operational perspective. Most pathogenic bacteria are inactivated by moisture reduction to below a threshold water activity, $\mathrm{a}_{\mathrm{w}}$, of $0.85[12,17]$. Drying can therefore assist in pasteurizing and sanitizing fresh feces, which can minimize the public health risks associated with managing the waste collected in onsite sanitation systems and for other fecal sludge management processes. Additionally, drying of fresh feces can reduce costs related to transportation and storage by decreasing the mass and volume of the material [18]. Finally, drying is a critical step in resource recovery methods such as compost production [19], fuel production [20], and production of building materials [18].

This work builds on exploratory research performed by Bourgault et al. [21] that justified the use of MSI to derive fundamental characteristics for fecal sludge. In addition to validating the approach explored by Bourgault et al. [21], this work evaluates the moisture sorption isotherm of fresh feces at three different temperatures with the objective of calculating the isoteric heat of sorption, a value that can be used to predict the energy requirements of drying.

\section{Materials and Methods}

Fresh feces samples were prepared and initially characterized $(\mathrm{pH}$, conductivity, chemical oxygen demand (COD), and moisture content). Equilibrium moisture content of the fresh feces samples were determined via a static gravimetric analysis, and MSIs were then modeled using non-linear least squares regression analysis. The heat of sorption for fresh feces was then calculated using the best-fitting model (as defined by the given statistical criteria described below).

\subsection{Sample Preparation and Initial Characterization}

Fresh feces samples were provided by healthy consenting volunteers $(n=6)$. Ethical approval was obtained from the University of Victoria (UVic) Human Research Ethics Board (HREB) prior to recruiting volunteers and procuring samples (Protocol Number 18-187). Volunteers were recruited from UVic (Victoria, BC, Canada). Samples were procured and all initial characterization was completed within two hours of defecation. 
Collected samples were gently homogenized, and an initial characterization of the $\mathrm{pH}$, chemical oxygen demand (COD), conductivity, and initial moisture content of the sample was performed. For determination of $\mathrm{pH}$ and electrical conductivity of feces, 1:400 m/v suspension with deionized water was made. The typical approach to measuring the $\mathrm{pH}$ and conductivity of fresh feces is to measure a homogenized sample rather than a sample in suspension [22-25], but the 1:400 suspension method was followed for consistency with exploratory work performed by Bourgault et al. [21].

$\mathrm{pH}$ and electricity conductivity were determined with an HQD portable meter and probe $(\mathrm{HACH}$, Loveland, CO, USA) (sensitivity of $\pm 0.02 \mathrm{pH}$ units; $\pm 1 \mu \mathrm{S} / \mathrm{cm}$, respectively) by immersion of the probe in the suspension. The moisture content analysis was performed using the oven method at $105{ }^{\circ} \mathrm{C}$ after final equilibrium moisture content was reached [26]. COD analysis was measured spectrophometrically (sensitivity of $\pm 14 \mathrm{mg}$ per L) using the reactor digestion method as per manufacturer's instruction (HACH method 8000).

\subsection{Equilibrium Moisture Content Determination}

Equilibrium moisture contents of fresh feces were determined experimentally in the Public Health \& Environmental Engineering (PH2E) Lab of UVic using the static gravimetric analysis proposed by Bourgault et al. [21] in the study of fecal sludge. This method has been validated as a technique to measure water distribution within waste activated sludge [8].

Seven saturated salt solutions were prepared corresponding to a range of water activities from 0.06 to 0.97 [27]. Each solution of $100 \mathrm{~mL}$ was poured into separate glass jars (i.e., experimental chambers) fitted with a polyethylene foam support to hold the fresh feces sample (Figure 1). A capillary tube of thymol was also placed in each jar to inhibit microbial growth, as per previous work [14]. Triplicate samples of about $1.5 \mathrm{~g}$ of fresh feces were weighed in aluminum crucibles and placed on supports in each jar which were then tightly closed and hermetically sealed with vacuum grease. Samples were spread on the crucible such that each had approximately the same surface area. The isotherm analysis began within $3 \mathrm{~h}$ of defecation. The samples were then placed in Peltier Incubators (VWR, Mississauga, ON, Canada) at $15{ }^{\circ} \mathrm{C}, 25^{\circ} \mathrm{C}$, and $35^{\circ} \mathrm{C}$ for equilibration. Each temperature-humidity combination was analyzed in triplicate. Specific experiments were also replicated with different sample masses (1.0 $\mathrm{g}, 1.5 \mathrm{~g}$, and $5.0 \mathrm{~g}$ ) and different sample donors to determine if sample mass or source of fresh feces sample had a statistically significant impact $(\alpha=0.05)$ on the equilibrium moisture content.

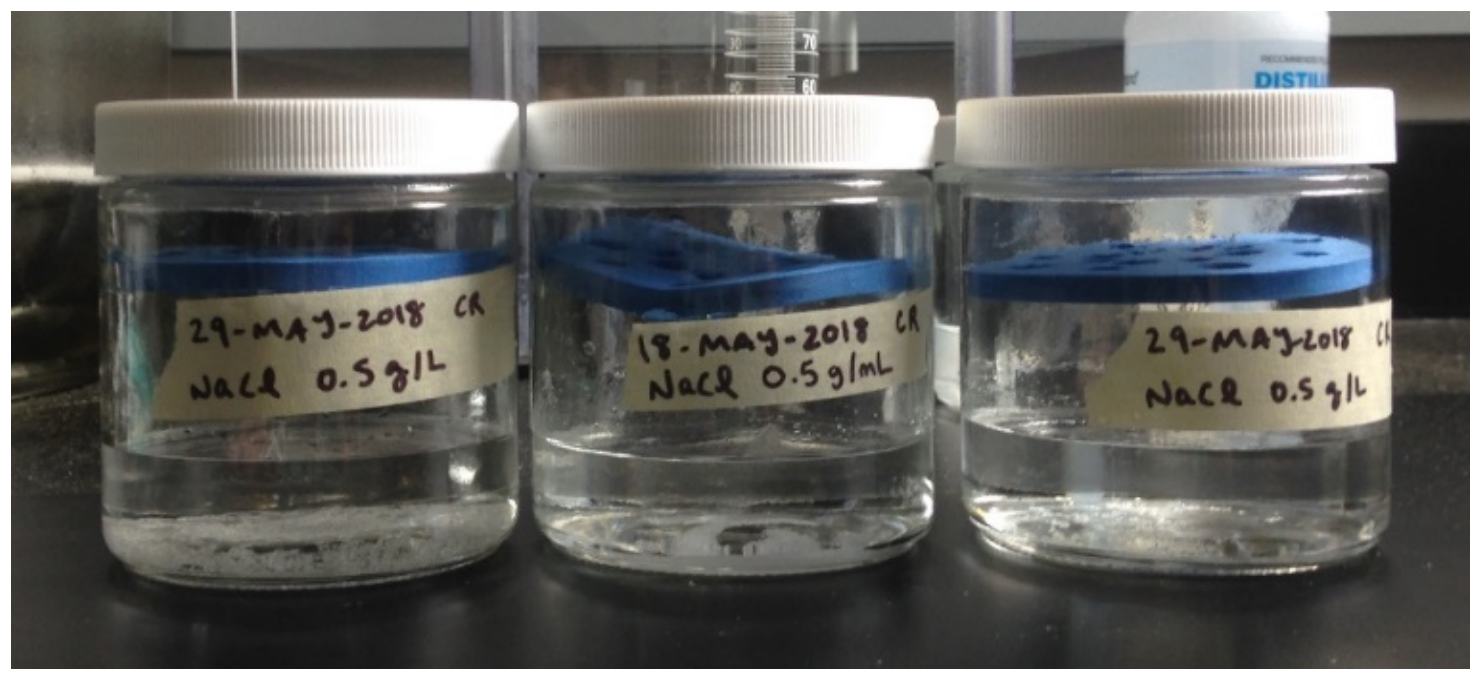

Figure 1. Each experimental chamber was prepared with $100 \mathrm{~mL}$ of saturated salt solution, a (blue) support (on which the sample was placed) and closed tightly with vacuum grease. A capillary tube of thymol was also placed in each jar to inhibit microbial growth. 
The required equilibration time was about 15 days based on the change in weight (dry basis) weighed at regular intervals $(24 \mathrm{~h}$ ) until the weighed mass varied by less than $2 \%$ for two consecutive weighings. The samples were weighed daily using a Sartorius QUINTIX analytical balance with an accuracy of $0.001 \mathrm{~g}$. The dry mass content was determined by oven drying at $105^{\circ} \mathrm{C}$ for $24 \mathrm{~h}$. The equilibrium moisture content was calculated on dry basis from the equilibrium mass and dry mass content (Equation (1) below).

$$
\mathrm{x}=\frac{\left(\mathrm{m}_{\mathrm{f}}-\mathrm{m}_{\mathrm{i}}\right)+\left(\frac{\% \mathrm{H}_{2} \mathrm{O}}{100} \cdot \mathrm{m}_{\mathrm{i}}\right)}{\mathrm{m}_{\mathrm{i}} \cdot\left(\frac{100-\left(\% \mathrm{H}_{2} \mathrm{O}\right)}{100}\right)}
$$

$\mathrm{x}=$ equilibrium moisture content (g water/g dry)

$\mathrm{m}_{\mathrm{f}}=$ final weight of sample at equilibrium

$\mathrm{m}_{\mathrm{i}}=$ initial weight of same sample

$\% \mathrm{H}_{2} \mathrm{O}=$ wet basis $\%$ moisture content of the wet sample

2.3. The Analysis of Correlation Between Equilibrium Moisture Content with Initial Characterization Data and the Multiple Linear Regression Analysis of the Effect of Temperature, Humidity, Sample Mass, and Donor on the Equilibrium Moisture Content

To test the correlations between the initial moisture content and the other initial characterization data (COD, conductivity, and $\mathrm{pH}$ ), a Pearson product-moment correlation coefficient was calculated $(\mathrm{n}=7)$.

A multiple linear regression was applied to analyze the effect of temperature, humidity, sample mass, and donor on the equilibrium moisture content and to determine which variables were significant. This served as a preliminary evaluation as to whether the data could be used to model a MSI for fresh feces. MSI do vary by temperature and humidity, but significant variation between donors (or the other independent variable, sample mass) might indicate that the data was too variable to generate a single MSI for fresh feces. The predictor variable "donor" is categorical and was transformed into a set of n-1 separate binary variables (i.e., "dummy coding"). The remaining predictor variables are continuous. The multiple linear regression model (Equation (2)) consisted of:

$$
x=\beta_{0}+\beta_{1} \cdot \text { Temperature }+\beta_{2} \cdot \text { Humidity }+\beta_{3} \cdot \text { Sample Mass }+\beta_{4} \cdot \text { Donor }+\varepsilon
$$

where $\beta_{0}, \beta_{1}$, etc. are regression coefficients and temperature, humidity, sample mass, and donor are various factors that may impact the equilibrium moisture content. The $p$-values associated with the individual factors were used to determine whether the factors were significant.

Both the Pearson coefficients and the multiple linear regression were computed in the $\mathrm{R}$ development core system [28]. Results were interpreted using a significance level $\alpha=0.05$.

\subsection{Modelling of MSI}

The experimental data was fitted to models by Equation (1), which estimated parameters for each temperature considered, and then Equation (2), which estimated parameters with the use of modified model versions that consider temperature dependence. The fit and prediction quality of the models were analyzed by the root mean squared error (RMSE) (Equation (3)), mean absolute percentage error (MAPE) (Equation (4)), and residual standard error (RSE) (Equation (5)); residuals are calculated as $\left(\hat{y}_{i}-y_{i}\right)$ (or the difference between the observed value and the value predicted by the model) [29].

$$
\begin{aligned}
& \text { RMSE }=\sqrt{\frac{\sum_{i=1}^{n}\left(\hat{y}_{i}-y_{i}\right)^{2}}{n}} \\
& \text { MAPE }=\frac{100 \%}{n} \sum_{i=1}^{n}\left|\frac{y_{i}-\hat{y}_{i}}{y_{i}}\right|
\end{aligned}
$$




$$
\operatorname{RSE}=\sqrt{\frac{\sum_{\mathrm{i}=1}^{\mathrm{n}}\left(\hat{\mathrm{y}}_{\mathrm{i}}-\mathrm{y}_{\mathrm{i}}\right)^{2}}{v}}
$$

The table below lists the mathematical isotherm models used in model fitting (Table 1). Several mathematical models are used to describe the sorption isotherms of food materials. It is necessary to test several models because no one equation is accurate for all materials for the complete range of water activities, because the way water is distributed within a solid is influenced by different mechanisms in different water activity regions [16]. Models were selected based on their use in describing biological materials with a higher moisture content $[8,13,21]$. Different models are most effective in describing the sorption isotherm at different $\mathrm{a}_{\mathrm{w}}$ levels as shown in the table below $[13,30,31]$.

Table 1. Selected isotherm models for fitting experimental data. The monolayer water content $\left(X_{m}\right)$ is assumed to be temperature independent and indicates the number of sorption sites available on the surface of the material. Different models are used to describe the moisture sorption isotherms (MSI) at different $\mathrm{a}_{\mathrm{w}}$ ranges (shown as " $\mathrm{a}_{\mathrm{w}}$ Range") and model fitting was done with a subset of the data associated with the referenced $a_{w}$ range.

\begin{tabular}{|c|c|c|c|c|}
\hline No. & Reference & Model & $a_{w}$ Range & Equation \\
\hline 1 & [13] & $\begin{array}{l}\text { Brunauer-Emmett-Teller } \\
\text { (BET) }\end{array}$ & $\mathrm{a}_{\mathrm{w}}<0.5$ & $X=\frac{X_{m} A_{a}}{\left(1-a_{w}\right)\left(1+(A-1) a_{w}\right)}$ \\
\hline 2 & [29] & Chin & $0<\mathrm{a}_{\mathrm{w}}<1$ & $X=\frac{A}{\ln a_{w}}+B$ \\
\hline 3 & [21] & Flory-Huggins & $0<\mathrm{a}_{\mathrm{w}}<1$ & $X=A \mathrm{e}^{\mathrm{Ba}_{\mathrm{w}}}$ \\
\hline 4 & {$[13]$} & GAB & $0.03<\mathrm{a}_{\mathrm{W}}<0.95$ & $X=\frac{X_{m} B A a_{w}}{\left(1-\mathrm{Aa}_{\mathrm{w}}\right)\left(1+(\mathrm{B}-1) \mathrm{Aa}_{\mathrm{w}}\right)}$ \\
\hline 5 & {$[13]$} & Lewicki (2-parameter) & $0<\mathrm{a}_{\mathrm{w}}<1$ & $X=A\left(\frac{1}{a_{w}}-1\right)^{b-1}$ \\
\hline 6 & [13] & Oswin & $0<\mathrm{a}_{\mathrm{w}}<1$ & $\mathrm{X}=\mathrm{A}\left(\frac{\mathrm{a}_{\mathrm{w}}}{1-\mathrm{a}_{w}}\right)^{\mathrm{B}}$ \\
\hline 7 & [13] & Smith & $0.5<\mathrm{a}_{\mathrm{w}}<0.95$ & $X=A+B \log \left(1-a_{w}\right)$ \\
\hline 8 & [30] & Halsey & $0<\mathrm{a}_{\mathrm{w}}<1$ & $X=\left(\frac{-A}{R T \ln \left(a_{w}\right)}\right)^{\frac{1}{B}}$ \\
\hline 9 & {$[8]$} & Modified Chung Pfost & $0<\mathrm{a}_{\mathrm{w}}<1$ & $X=\frac{-1}{A} \cdot \ln \left(-\ln \left(a_{w}\right) \cdot \frac{T+B}{C}\right)$ \\
\hline 10 & {$[31]$} & Modified Oswin & $0<\mathrm{a}_{\mathrm{w}}<1$ & $\mathrm{X}=\left(\mathrm{k}_{1}+\mathrm{k}_{2} \cdot \mathrm{T}\right)\left(\frac{\mathrm{a}_{\mathrm{w}}}{1-\mathrm{a}_{\mathrm{w}}}\right)^{\left(\mathrm{k}_{3}+\mathrm{k}_{4} \cdot \mathrm{T}\right)}$ \\
\hline
\end{tabular}

The parameters of the models were determined using non-linear least squares regression analysis in the R development core system [28]. To evaluate the ability of each model's fit to the experimental data, the RMSE, MAPE, and RSE were computed.

\subsection{Determination of Heat of Sorption from the MSI}

The heat of sorption was calculated based on the model with the best fit to the experimental data over the entire $\mathrm{a}_{\mathrm{w}}$ range (i.e., the lowest RMSE, lowest MAPE, and lowest RSE). Generally, a MAPE of less than $10 \%$ justifies the use of the model for describing experimental data; and low values of RMSE and RSE are expected for models that adequately describe the data [13].

$$
\ln \left(\mathrm{a}_{\mathrm{w}}\right)=-\frac{\Delta \mathrm{H}}{\mathrm{R}} \frac{1}{\mathrm{~T}}+\text { constant }
$$

The heat of sorption was calculated following established methods [8,13,32]. Equation (6) is derived from the Clausius-Clapeyron equation where $\Delta \mathrm{H}$ is the heat of sorption, $\mathrm{R}$ is the gas constant $(8.3145 \mathrm{~J} / \mathrm{mol} \mathrm{K})$, and $\mathrm{T}$ is the temperature in Kelvin [8].

Using the best-fitting MSI model, $\mathrm{a}_{\mathrm{w}}$ can be estimated for a given moisture constant. The slope of the plot of $\ln \left(a_{w}\right)$ vs. $1 / T$ can then be used to calculate the heat of sorption. The mathematical relationship between the heat of sorption and the equilibrium moisture content was fitted in the $\mathrm{R}$ development core system using the nonlinear least squares method. Confidence bands for the 
relationship were generated using an error propagating function [33]. The fitted relationship was used to estimate energy requirements for drying.

\section{Results and Discussion}

For the given samples, the $\mathrm{pH}$ was $7.7 \pm 0.3$ (average \pm standard deviation) and the conductivity was $86 \pm 19 \mu \mathrm{S} / \mathrm{cm}$ (average \pm standard deviation). Results from the initial COD and moisture content characterization analysis are summarized in Table 2 and compared with literature values.

Table 2. Comparison of results from characterization of fresh feces samples $(n=7)$ with literature values. When available, values given as averages \pm standard deviation.

\begin{tabular}{cccc}
\hline & & \multicolumn{2}{c}{ Comparison to Literature Values } \\
\hline Characteristic & Result & Rose et al. [15] & Bourgault et al. [21] \\
\hline COD (mg per g dry feces) & $1366 \pm 106$ & 567 to 1450 & $1395 \pm 293$ \\
Moisture content (\%) & $76 \pm 5 \%$ & $63 \%$ to $86 \%$ & $80 \pm 3 \%$ \\
\hline
\end{tabular}

Both the measured COD and moisture content are within the ranges reported in Rose et al. [15] and Bourgault et al. [21]. The values reported by Rose et al. [15] represent a literature survey of 47 samples. Variation in moisture content was attributed to differences in fiber intake: individuals with vegetarian diets will have a higher moisture content than those who consume less fiber and more protein. Similarly, COD was used to measure the bulk organic content of feces; this depends on dietary intake and its biological availability [15]. The narrower range measured in this analysis may have indicated that the samples in the study were limited with respect to geographical and dietary representation.

Initial moisture content was correlated with COD (Pearson's correlation coefficient $=-0.92, p<$ 0.01 ) and conductivity (Pearson's correlation coefficient $=-0.97, p<0.01$ ). Initial moisture content was poorly correlated with $\mathrm{pH}$ (Pearson's correlation coefficient $=0.23, p=0.62$ ). From a qualitative perspective, many samples were observed to have undigested food particles and there was variation in both odor and texture.

Both temperature and humidity had a significant impact on equilibrium moisture content at a significance level of $\alpha=0.05$ (Table 3). This was expected as equilibrium moisture content represents a solid's moisture content at the thermodynamic equilibrium given relative humidity and temperature conditions [14]. Neither the sample mass nor the donor had a significant impact on equilibrium moisture content at a significance level at $\alpha=0.05$ (but donor had a significant impact on equilibrium moisture content at a significance level at $\alpha=0.10$ ). This finding should be caveated with the note that analysis is based on a small sample size and could be validated in further research.

Table 3. Summary of regression coefficients for multiple linear regression model (Equation (2)) (ANOVA, $\mathrm{F}(4,394)=39.38, p$-value $<0.01)$ relating to equilibrium moisture content with the factors of temperature, humidity, sample mass, and donor.

\begin{tabular}{cccc}
\hline Variable & Estimate & Standard Error & Significance $(p$-Value $)$ \\
\hline Intercept & 0.19 & 0.18 & 0.28 \\
Temperature & -0.010 & 0.0048 & 0.034 \\
Humidity & 1.33 & 0.11 & $>0.001$ \\
Sample Mass & -0.0065 & 0.063 & 0.92 \\
Donor1 & -0.21 & 0.14 & 0.14 \\
Donor2 & 0.24 & 0.14 & 0.099 \\
Donor3 & 0.062 & 0.22 & 0.78 \\
Donor4 & -0.19 & 0.11 & 0.074 \\
\hline
\end{tabular}


Equilibrium moisture content of fresh feces at three temperature levels of 15,25 , and $35^{\circ} \mathrm{C}$ in the range of 6-97\% relative humidity values are shown in Figure 2. Most samples required 2-4 weeks to reach equilibrium. The isotherm curves demonstrated a roughly sigmoid shape and there is a general decrease in equilibrium moisture contents with increasing temperature. The range of values at higher relativity humidity values is greater because at a relative humidity of $100 \%$, the sorption isotherm tended to a vertical asymptote, which caused an increased variance at higher relative humidity values.

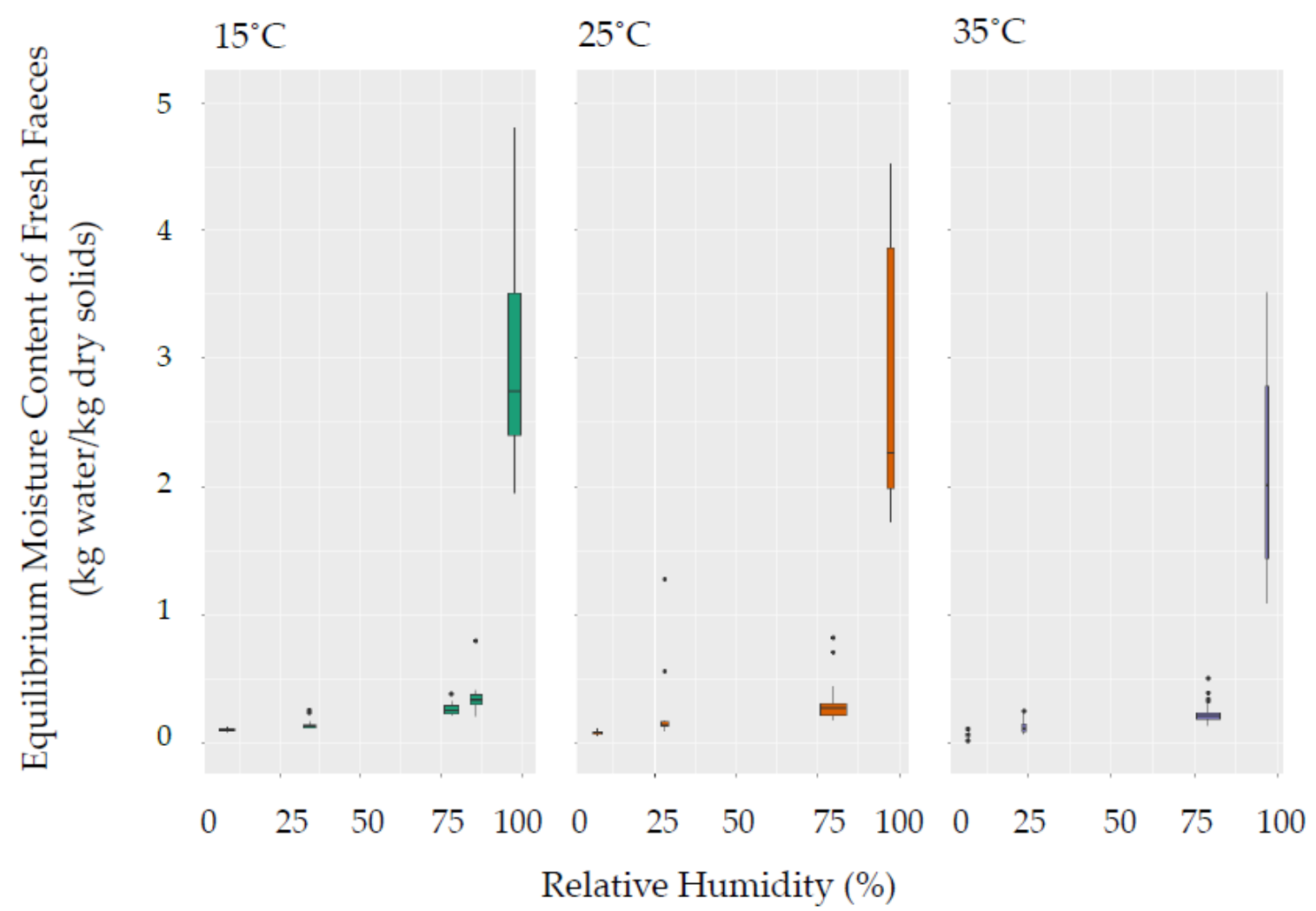

Figure 2. Box plots of equilibrium moisture content data at temperatures of 15,25 and $35{ }^{\circ} \mathrm{C}$ with a sample mass of $1.5 \mathrm{~g}$. The data suggests a sigmoidal sorption isotherm with two inflection points. At a relative humidity of $100 \%$, the sorption isotherm tends to a vertical asymptote, which causes an increased variance at higher relative humidity.

Equilibrium moisture content depends on the nature of the given solid in addition to the operating conditions. Sorption isotherms give an indication of the binding mechanism of moisture in sludge [34]. In general, it can be seen in Figure 2 that at a higher temperature, the equilibrium moisture content that corresponded to a given water activity is lower. Equilibrium moisture content has been considered as a parameter to characterize water distribution: whether it is chemically bound, internal water, or intracellular water [14]. The pattern of the sorption isotherm depends on the temperature and water-solid interactions $[14,17]$. Table 4 shows the parameter estimates as well as the calculated error criterion (Equations (3)-(5)) for various models used to describe sorption isotherms. 
Table 4. Model fit coefficients and error criterion.

\begin{tabular}{|c|c|c|c|c|c|c|c|c|c|}
\hline \multirow[t]{2}{*}{ Model } & \multirow{2}{*}{$\begin{array}{c}\text { Temp } \\
(\circ \mathrm{C})\end{array}$} & \multicolumn{5}{|c|}{$\begin{array}{l}p \text {-Values for the Model Fit } \\
\text { Coefficients }\end{array}$} & \multirow[t]{2}{*}{ RMSE } & \multirow[t]{2}{*}{ MAPE } & \multirow[t]{2}{*}{ RSE } \\
\hline & & $X_{m} *$ & A & B & $\mathrm{C}$ & D & & & \\
\hline \multirow{3}{*}{ BET } & 15 & $<0.01$ & 0.53 & & & & 0.027 & 0.127 & 0.619 \\
\hline & 25 & & 0.83 & & & & 0.184 & 0.259 & 0.956 \\
\hline & 35 & & $<0.01$ & & & & 0.036 & 0.365 & 0.600 \\
\hline \multirow{3}{*}{ Chin } & 15 & & $<0.01$ & 0.97 & & & 0.442 & 0.456 & 0.130 \\
\hline & 25 & & $<0.01$ & 0.59 & & & 0.363 & 0.384 & 0.171 \\
\hline & 35 & & $<0.01$ & 0.94 & & & 0.305 & 0.443 & 0.160 \\
\hline \multirow{3}{*}{ Flory-Huggins } & 15 & & 0.63 & $<0.01$ & & & 0.448 & 0.687 & 0.133 \\
\hline & 25 & & 0.46 & $<0.01$ & & & 0.375 & 0.654 & 0.181 \\
\hline & 35 & & 0.36 & $<0.01$ & & & 0.308 & 0.624 & 0.163 \\
\hline \multirow{3}{*}{ GAB } & 15 & & $<0.01$ & 0.76 & & & 0.067 & 0.137 & 0.320 \\
\hline & 25 & & $<0.01$ & 0.84 & & & 0.157 & 0.241 & 0.787 \\
\hline & 35 & & $<0.01$ & $<0.01$ & & & 0.046 & 0.269 & 0.275 \\
\hline \multirow{3}{*}{ Lew } & 15 & & 0.03 & 0.57 & & & 0.441 & 0.536 & 0.129 \\
\hline & 25 & & $<0.01$ & 0.73 & & & 0.365 & 0.554 & 0.173 \\
\hline & 35 & & $<0.01$ & 0.497 & & & 0.304 & 0.523 & 0.160 \\
\hline \multirow{3}{*}{ Oswin } & 15 & & 0.03 & $<0.01$ & & & 0.441 & 0.536 & 0.130 \\
\hline & 25 & & $<0.01$ & $<0.01$ & & & 0.365 & 0.554 & 0.173 \\
\hline & 35 & & $<0.01$ & $<0.01$ & & & 0.304 & 0.523 & 0.160 \\
\hline \multirow{3}{*}{ Smith } & 15 & & 0.33 & $<0.01$ & & & 0.093 & 0.149 & 0.730 \\
\hline & 25 & & 0.61 & 0.24 & & & 0.120 & 0.215 & 0.966 \\
\hline & 35 & & 0.09 & $<0.01$ & & & 0.050 & 0.156 & 0.681 \\
\hline Halsey & all & & $<0.01$ & $<0.01$ & & & 0.366 & 0.462 & 0.149 \\
\hline $\begin{array}{c}\text { Modified Chung } \\
\text { Pfost }\end{array}$ & all & & $<0.01$ & $<0.01$ & 0.04 & & 0.652 & 2.77 & 0.475 \\
\hline Modified Oswin & all & & 0.01 & 0.02 & 0.32 & 0.05 & 0.364 & 0.545 & 0.148 \\
\hline
\end{tabular}

The Smith, GAB, and BET models provided the best fit to the experimental data for their respective $a_{w}$ ranges, but the GAB model provides the best fit to the experimental data on the entire $a_{w}$ range when considering all three error criteria and an expected increase in equilibrium moisture content with increased temperatures (Figure 3). The Smith model coefficients did not demonstrate the expected increase in equilibrium moisture content with decreasing temperature. The GAB model has been reported to give a good fit for over $75 \%$ of food isotherms: starchy foods, fruits, vegetables, and meat products [16]. Given that feces will be most like food in terms of molecular composition, it makes sense that the GAB model fits well.

The heat of sorption was calculated from the plot of $\ln \left(a_{w}\right)$ vs. 1/T with the GAB model (Figure 4). The total heat of evaporation was significant up to a moisture content of about $0.2 \mathrm{~kg}$ water per $\mathrm{kg}$ dry solids (at this moisture content, the curve becomes asymptotic (Figure 4)). 

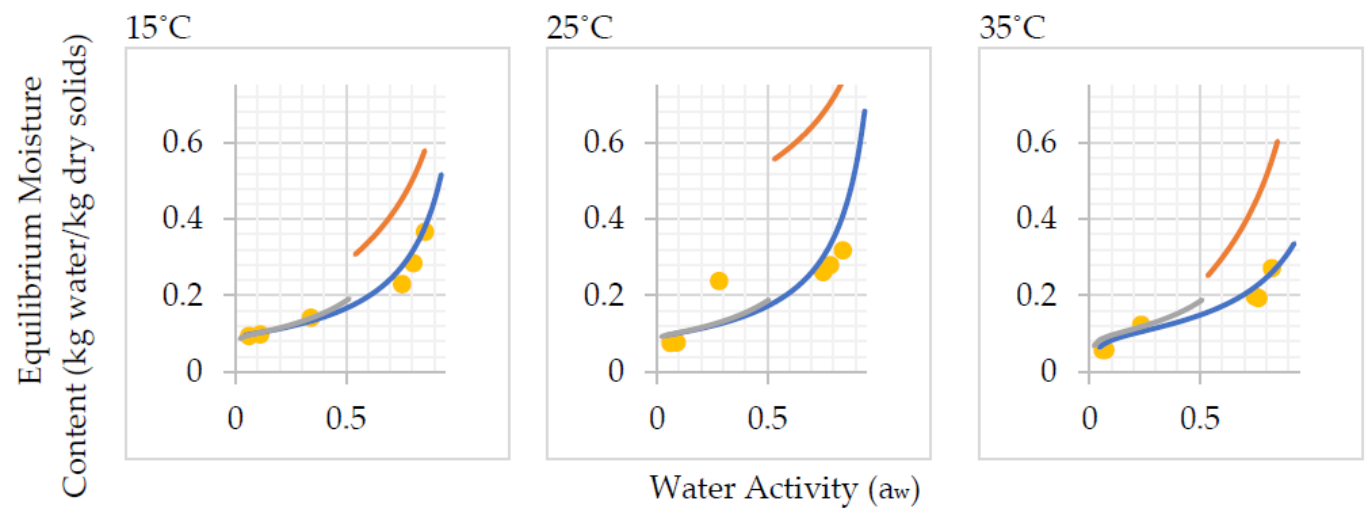

Figure 3. Comparison of predicted sorption isotherm curve for fresh feces using the BET, GAB, and Smith models with experimental equilibrium moisture contents. The dots represent the experimental average. The GAB model was fitted to the entire activity range and both the Smith and BET models were fitted to the activity range that they are used to describe (Table 2).

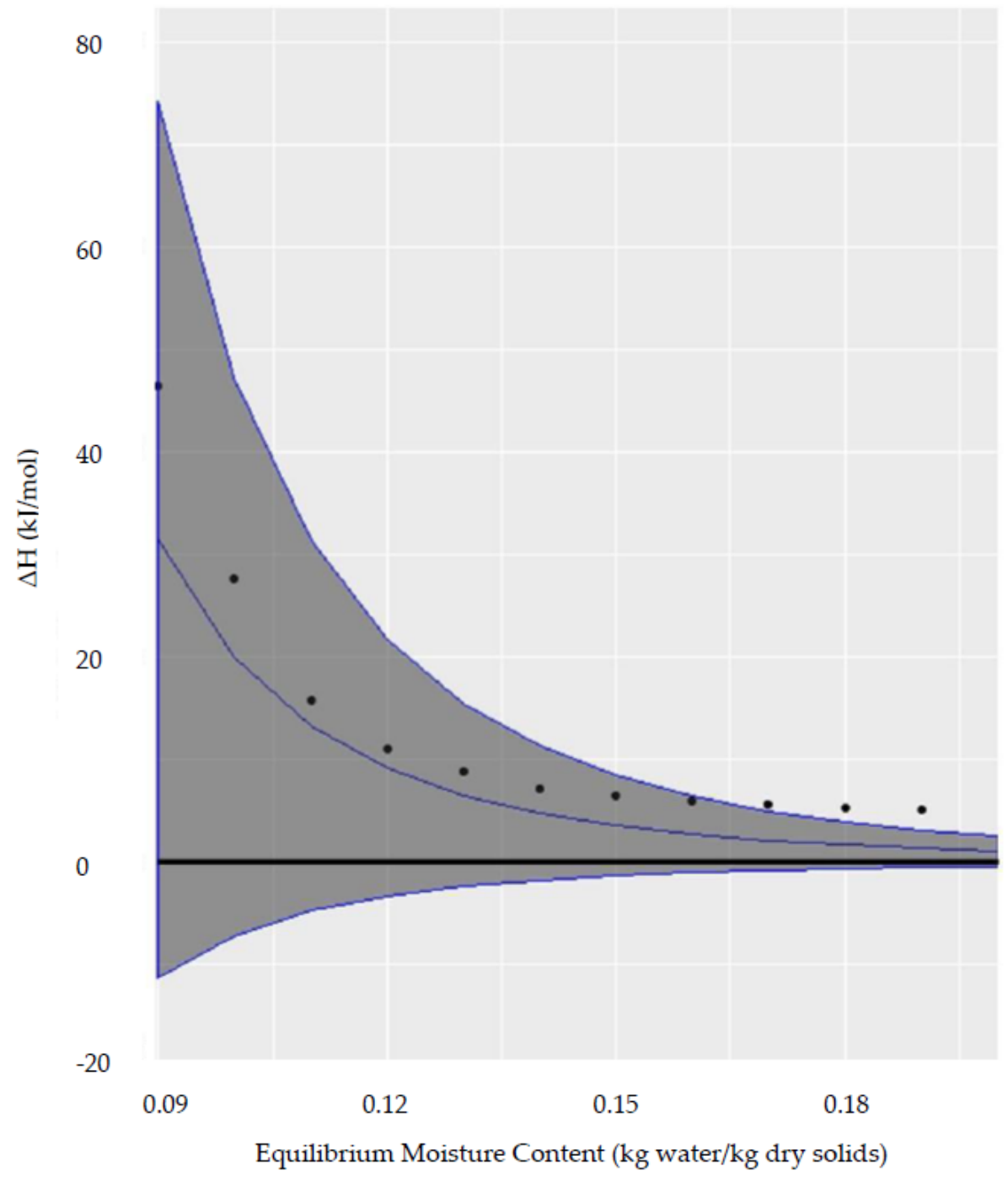

Figure 4. Heat of sorption of fresh feces versus moisture content; calculated with the GAB equation. The relationship between heat of sorption and equilibrium moisture content $(\mathrm{x})$ was fitted as $\Delta \mathrm{H}=$ $0.001505(x)^{-4.277039}$ using the nonlinear least squares method in R. Confidence bands on the relationship were generated using an error propagating function. 
The heat of sorption is important when designing equipment for the drying and dewatering process [16]. As can be seen in Figure 4, the heat of sorption decreases as the moisture content increases. This suggests that an increasing amount of energy is required as moisture content of fresh feces increases, and dryers should be designed to account for the differing degree to which water is bound to the solid and thus how much energy is required to remove it. More significantly, it may be of interest to design dryers for an intended final water activity that achieves a given treatment goal. For example, evaporation results in desiccation or dehydration that inactivates pathogen; although some yeast and eggs survive in drier conditions, many fecal-borne pathogens cannot survive at a water activity of less than 0.9 [18].

Most pathogens are inactivated at $\mathrm{a}_{\mathrm{w}}$ lower than 0.85 [6]. For the given data and analysis performed in this experiment, an $\mathrm{a}_{\mathrm{w}}$ of 0.85 corresponds to a moisture content of $27 \%$ to $34 \%$ over temperatures of $15^{\circ} \mathrm{C}, 25^{\circ} \mathrm{C}$, and $35^{\circ} \mathrm{C}$. Given an anticipated range of initial moisture contents of $63 \%$ to $86 \%$, this translates to an estimated energy requirement of 0.05 to $0.4 \mathrm{~kJ} / \mathrm{mol}$ (Table 5).

Table 5. Calculation of the energy requirements for drying fresh feces from an initial moisture content of $63 \%$ to $86 \%$ to the moisture content corresponding to $\mathrm{a}_{\mathrm{w}}$ of 0.85 at a temperature range of $15-35$ ${ }^{\circ} \mathrm{C}$. The relationship between $\mathrm{a}_{\mathrm{w}}$ and moisture content calculated using the GAB relationship and the relationship between moisture content and the heat of sorption calculated with the fitted relationship described in Figure 4.

\begin{tabular}{cccc}
\hline & $\mathbf{a}_{\mathbf{w}}$ & Moisture Content & $\begin{array}{c}\text { Drying Energy } \\
\text { Requirements }\end{array}$ \\
\hline Initial & 0.93 to 1 & $63 \%$ to $86 \%$ & \\
Pathogen inactivation & $<0.85$ & $27 \%$ to $34 \%$ & 0.05 to $0.40 \mathrm{~kJ} / \mathrm{mol}$ \\
Difference & 0.08 to 0.15 & $29 \%$ to $59 \%$ & \\
\hline
\end{tabular}

However, this analysis of energy requirements is based on a limited set of data that has enough variability to be non-representative of fresh feces as a generalizable matrix. Further investigation of the $\mathrm{a}_{\mathrm{w}}$ characteristics of fecal sludge beyond first efforts [21] is still required to develop technologies and processes for fecal sludge management beyond the initial containment (and treatment) of fresh feces.

There are no data available regarding the energy requirements for drying fresh feces. There is some literature that discusses the energy requirements of dewatering sewage and pit latrine sludge as a pre-pyrolysis step in the production of biochar [35,36]. However, these studies consider only the energy requirements of the dewatered sludge as the drying step is performed by a variety of technologies where energy requirements remain unmeasured [11]. These studies do acknowledge that pretreatment (i.e., drying) is a critical processing step as human feces as a high moisture content.

Since there are no readily available energy values available for comparison, the following is a comparison of the equilibrium moisture content of fresh feces measured in the study with that measured by Bourgault et al. [21] for fecal sludge and by Vaxelaire et al. [8] for waste activated sludge.

The values of equilibrium moisture content for the three matrices described in Figure 5 are on the same order of magnitude. Variation between the values can be attributed to a combination of temperature (the values for equilibrium moisture content for waste activated sludge were evaluated at $39^{\circ} \mathrm{C}$ compared to $35^{\circ} \mathrm{C}$ for fresh feces and fecal sludge) and chemical composition. Bourgault et al. [21] concluded from the data that water in fresh feces appears to be more easily extracted from a water activity of 1 to 0.75 (corresponding to a relative humidity of $100 \%$ to $75 \%$ ). The water corresponding to this range of water activity may correspond to "free water." Free water is that moisture within the solid that exists with unhindered mobility [16]. In comparison, it appears that the bound water in fresh feces corresponds to a higher water activity range (greater than $85 \%$ ). The variation in bound or unbound water is dependent on water-solid interactions and is an inherent thermodynamic property. 


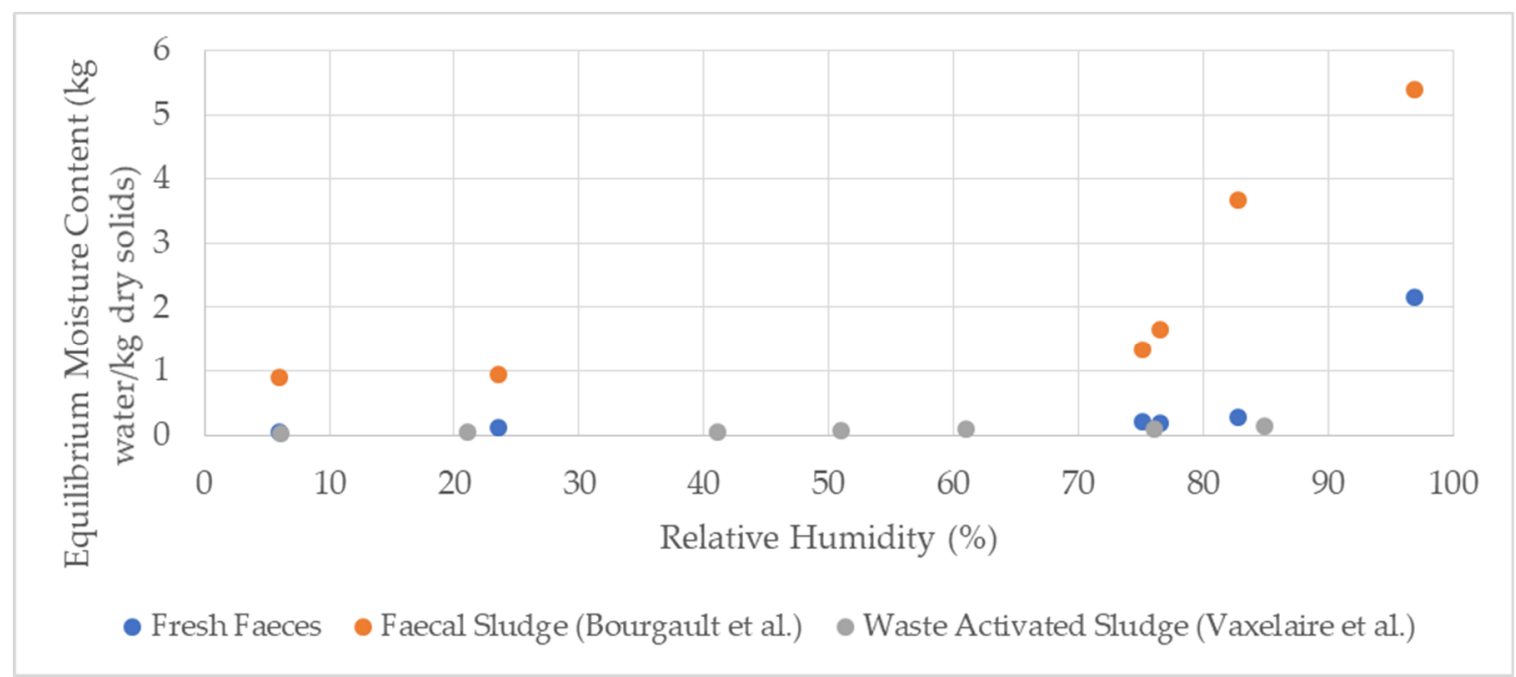

Figure 5. Comparison of equilibrium moisture content of fresh feces at $35^{\circ} \mathrm{C}$ (measured in the present analysis), fecal sludge $35^{\circ} \mathrm{C}$ [21], and waste activated sludge at $39^{\circ} \mathrm{C}$ [8].

Bourgault et al. [21] evaluated the use of three models and concluded that the use of the GAB model is most appropriate for representing the sorption isotherm of fecal sludge. The GAB model has been described as the most versatile sorption model and has a viable theoretical background based on principles of moisture's physical adsorption properties [16]. Vaxelaire et al. [8] concluded that the GAB equation enables good modeling at a given temperature but has poor fitting when modeling at varied temperatures; Vaxelaire et al. [8] instead justified the use of the Oswin model to describe the sorption isotherm of waste activated sludge based on selected statistical criteria. The Oswin model is an empirical model that is recommended for describing the isotherms of starchy foods [16]. However, this model did not perform as well for the experimental conditions studied here (Table 4).

\section{General Discussion}

There is significant literature available to describe the dewatering and moisture distribution characteristics of conventional activated sludge. The methods used in wastewater can be applied to fecal sludge and fresh feces moisture distribution characteristics. One method that has been identified in wastewater literature is the moisture sorption isotherm technique used in this study [14]. This study represents a significant advance towards producing the same key criteria for fresh feces that exists for waste activated sludge using a method identified in the wastewater sludge.

According to the multivariable linear regression model, both temperature and humidity have a significant impact on equilibrium moisture content at a significance level of $\alpha=0.05$ (Table 3). Neither the sample mass nor the donor were statistically significant. However, a variability in chemical composition - and therefore the $\mathrm{a}_{\mathrm{w}}$ characteristics—would be expected in individual feces samples (and even for a single individual over time), and it is possible that the lack of significance in this case was due to the limited sample size.

In response to this, it may be possible to develop a universal MSI by analyzing the chemical composition of fresh feces' samples (or alternatively using COD measurements as a proxy for chemical composition). In other words, a MSI could be developed by understanding fresh feces as a composite of chemicals. Moreira et al. [37] developed a simple algorithm to predict the water sorption isotherm of fruits, vegetables, and legumes based upon chemical composition (i.e., protein, fiber, starch, glucose, fructose, sucrose, salt, and other). The advantage of a universal MSI for fresh feces would be to support the development of a sanitation system capable of achieving in situ pathogen inactivation objectives via drying. 
The drying of fresh feces and fecal sludge is a productive step in the management of sanitation and waste treatment services. One focus of recent research in sanitation engineering in low- and middle-income countries is the development of low resource-use technologies (e.g., the development of on-site sanitation systems that function without water) [38]. A recent study by Eekert et al. [39] suggested that the anaerobic biodegradation of solids in pit latrines could be improved with the addition of freshwater. However, it has also contended that this practice could hinder aerobic biodegradation mechanisms in pit latrines [40]. Furthermore, in general, there is a growing recognition of declining freshwater availability at the global and local scales and, as such, waterborne sanitation systems are potentially advantageous in all contexts: low-, middle-, and high-income countries [41,42]. Additionally, the advantages of drying in fecal sludge management include increased pathogen inactivation [43] and the reduction of costs related to transport and treatment of fecal sludge [18]. An improved understanding of fresh feces and fecal sludge drying contributes to the development and deployment of sanitation and waste treatment management services that are adaptive to shifting freshwater availability.

In general, fresh feces and fecal sludge are matrices that have not been well-characterized from the perspective of improved sanitation, waste treatment, and resource recovery technological development and service provision $[15,37,44]$. This work contributes to an improved characterization of fresh feces as well as an elaboration of an experimental technique that could be applied to fecal sludge. Future work includes comparing this data with fecal sludge from varied sources to compare the physical water distribution of fresh feces with fecal sludge, integrating characterization data (e.g., COD) or chemical composition into MSI models, and determining the relationship between $\mathrm{a}_{\mathrm{w}}$ and pathogen inactivation.

There is additional interest in investigating the applicability of this research to composting toilet designs (such as that discussed in Section 4). For example, this data could be used to investigate if composting toilet designs that operate by passive ventilation generate enough drying energy to achieve in situ pathogen inactivation objectives.

\section{Conclusions}

The objective of this work was to describe the MSI of fresh feces and the corresponding energy requirements for drying. This work produced the first set of desiccation data on fresh feces. This data is useful in the design of systems and processes that treat and manage feces by drying, but there is no information available in the literature. A static gravimetric analysis was used to derive experimental sorption isotherms at 15,25 , and $35^{\circ} \mathrm{C}$. The GAB equation best fitted the experimental data over the entire $a_{w}$ range and was used to derive the heat of sorption. The heat of sorption curve shows the heat of evaporation is significant up to a moisture content of about $0.2 \mathrm{~kg}$ water per $\mathrm{kg}$ dry solid.

Author Contributions: Conceptualization, C.R., C.B. and C.C.D.; methodology, C.R. and C.D.; validation, C.R. and C.B.; formal analysis, C.R.; investigation, C.R.; data curation, C.R.; writing-original draft preparation, C.R.; writing-review and editing, C.C.D.; supervision, C.C.D.; project administration, C.C.D.; funding acquisition, C.C.D. All authors have read and agreed to the published version of the manuscript.

Funding: This research was supported by the Humanitarian Innovation Fund and Mitacs (grant number 1718-19227).

Acknowledgments: We would like to thank the technical team of the Department of Civil Engineering (UVic) for their support throughout this study.

Conflicts of Interest: The authors declare no completing interests. The funders had no role in the design of the study; in the collection, analyses, or interpretation of data; in the writing of the manuscript, or in the decision to publish the results.

\section{References}

1. WHO \& UNICEF. Sanitation. Available online: https://washdata.org/monitoring/sanitation (accessed on 15 June 2019). 
2. Cairns-Smith, S.; Hill, H.; Nazarenko, E. Urban Sanitation: Why a Portfolio of Solutions is Needed; The Boston Consulting Group: Boston, MA, USA, 2014.

3. Webb, C.; Cabada, M.M. A Review on Prevention Interventions to Decrease Diarrheal Diseases' Burden in Children. Curr. Trop. Med. Rep. 2018, 5, 31-40. [CrossRef]

4. Harris, D.; Kooy, M.; Jones, L. Analysing the governance and political economy of water and sanitation service delivery. Lond. Over Sea Dev. Inst. 2011, 27, 2013.

5. Hutton, G. Global Costs and Benefits of Drinking-Water Supply and Sanitation Interventions to Reach the MDG Target and Universal Coverage; World Health Organ: Geneva, Switzerland, 2012.

6. Effect of Drying Temperature and Drying Air Velocity on the Drying Rate and Drying Constant of Cocoa Bean. Available online: https://cigrjournal.org/index.php/Ejounral/article/viewFile/1091/1172 (accessed on 22 January 2020).

7. Erbay, Z.; Icier, F. A review of thin layer drying of foods: Theory, modeling, and experimental results. Crit. Rev. Food Sci. Nutr. 2010, 50, 441-464. [CrossRef] [PubMed]

8. Vaxelaire, J. Moisture sorption characteristics of waste activated sludge. J. Chem. Technol. Biotechnol. 2001, 76, 377-382. [CrossRef]

9. Bond, T.; Tse, Q.; Chambon, C.L.; Fennell, P.; Fowler, G.D.; Templeton, M.R. The feasibility of char and bio-oil production from pyrolysis of pit latrine sludge. Environ. Sci. Water Res. Technol. 2018, 4, 253-264. [CrossRef]

10. Ward, B.J.; Yacob, T.W.; Montoya, L.D. Evaluation of solid fuel char briquettes from human waste. Environ. Sci. Technol. 2014, 48, 9852-9858. [CrossRef]

11. Liu, X.; Li, Z.; Zhang, Y.; Feng, R.; Mahmood, I.B. Characterization of human manure-derived biochar and energy-balance analysis of slow pyrolysis process. Waste Manag. 2014, 34, 1619-1626. [CrossRef]

12. Hui, Y.; Clary, C.; Farid, M.M.; Fasina, O.; Noomhorm, A.; Welti-Chanes, J. Food Drying Science and Technology: Microbiology, Chemistry, Applications; DEStech Publications Inc.: Lancaster, PA, USA, 2008.

13. Gutiérrez-López, G.F.; Alamilla-Beltrán, L.; del Pilar Buera, M.; Welti-Chanes, J.; Parada-Arias, E.; Barbosa-Cánovas, G.V. Water Stress in Biological, Chemical, Pharmaceutical and Food Systems; Springer: Berlin/Heidelberg, Germany, 2015.

14. Vaxelaire, J.; Cézac, P. Moisture distribution in activated sludges: A. review. Water Res. 2004, 38, $2215-2230$. [CrossRef]

15. Rose, C.; Parker, A.; Jefferson, B.; Cartmell, E. The characterization of feces and urine: A review of the literature to inform advanced treatment technology. Crit. Rev. Environ. Sci. Technol. 2015, 45, 1827-1879. [CrossRef]

16. Al-Muhtaseb, A.H.; McMinn, W.A.M.; Magee, T.R.A. Moisture sorption isotherm characteristics of food products: A review. Food Bioprod. Process. Trans. Inst. Chem. Eng. Part C 2002, 80, 118-128. [CrossRef]

17. Stringel, S.S.; Mugauri, T.; Singh, A.; Inambao, F. Drying of Faecal Sludge Using Solar Thermal Energy; Water Resources Commission: Durban, South Africa, 2016.

18. Strande, L.; Ronteltap, M.; Brdjanovic, D. Faecal Sludge Management: Systems Approach for Implementation and Operation; IWA Publishing: London, UK, 2014.

19. Seck, A.; Gold, M.; Niang, S.; Mbeguere, M.; Diop, C.; Strande, L. Faecal sludge drying beds: Increasing drying rates for fuel resource recovery in Sub-Saharan Africa. J. Water Sanit. Hyg. Dev. 2015, 5, 72-80. [CrossRef]

20. Cottingham, R.; Mercer, S.; Buckley, C.; Still, D. Economic Evaluation of Faecal Sludge Disposal Routes Phase 5; Pollution Research Group at University of KwaZulu-Natal: Durban, South Africa, 2013.

21. Bourgault, C.; Lessard, P.; Remington, C.; Dorea, C.C. Experimental determination of moisture sorption isotherm of fecal sludge. Water 2019, 11,303. [CrossRef]

22. Faassen, V.; Hazen, J.; van den Brandt, P.A.; van den Bogaard, A.E.; Hermus, R.J.; Janknegt, R.A. Bile acids and $\mathrm{pH}$ values in total feces and in fecal water from habitually omnivorous and vegetarian subjects. Am. J. Clin. Nutr. 1993, 58, 917-922. [CrossRef] [PubMed]

23. Walker, A.R.P.; Walker, B.F.; Segal, I. Faecal pH Value and its Modification by Dietary Means In South African Black and White Schoolchildren. S. Afr. Med. J. 1979, 55, 495-498.

24. Phillips, J.; Muir, J.G.; Birkett, A.; Lu, Z.X.; Jones, G.P.; O’Dea, K.; Young, G.P. Effect of resistant starch on fecal bulk and fermentatio-dependent events in humans. Am. J. Clin. Nutr. 1995, 62, 121-130. [CrossRef] 
25. Silvester, K.R.; Bingham, S.A.; Pollock, J.R.A.; Cummings, J.H.; O’Neill, I.K. Effect of meat and resistant starch on fecal excretion of apparent $\mathrm{N}$ - nitroso compounds and ammonia from the human large bowel. Nutr. Cancer 1997, 29, 13-23. [CrossRef]

26. Association of Official Analytical Chemists. Official Methods of Analysis; AOAC International: Rockville, MD, USA, 1990; pp. 17-18.

27. Bell, L.N.; Labuza, T.P. Moisture Sorption: Practical Aspects of Isotherm Measurement and Use, 2nd ed.; American Association of Cereal Chemists: St. Paul, MN, USA, 2000.

28. Team, R.C. R: A Language and Environment for Statistical Computing; R Foundation for Statistical Computing: Vienna, Austria, 2013.

29. Sopade, P.A. Criteria for an appropriate sorption model based on statistical analysis. Int. J. Food Prop. 2001, 4, 405-418. [CrossRef]

30. Akanbi, C.T.; Adeyemi, R.S.; Ojo, A. Drying characteristics and sorption isotherm of tomato slices. J. Food Eng. 2006, 73, 157-163. [CrossRef]

31. Janjai, S.; Lamlert, N.; Tohsing, K.; Mahayothee, B.; Bala, B.K.; Müller, J. Measurement and modeling of moisture sorption isotherm of litchi (Litchi Chinensis Sonn.). Int. J. Food Prop. 2010, 13, 251-260. [CrossRef]

32. Al-Mahasneh, M.; Al-Wdyan, M.I.; Rababah, T.; Alu'Datt, M. Moisture sorption thermodynamic properties of Bermuda grass. Bulg. J. Agric. Sci. 2017, 23, 682-687.

33. Speiss, A.-N. Propagate, rdocumentation.org. Available online: https://www.rdocumentation.org/packages/ propagate/versions/1.0-6/topics/propagate (accessed on 15 June 2019).

34. Herwijn, A.J.M. Fundamental Aspects of Sludge Characterization. Ph.D. Thesis, Technische Universiteit Eindhoven, Eindohoven, The Netherlands, April 1996.

35. Ma, W.; Du, G.; Li, J.; Fang, Y.; Hou, L.A.; Chen, G.; Ma, D. Supercritical water pyrolysis of sewage sludge. Waste Manag. 2017, 59, 371-378. [CrossRef] [PubMed]

36. McNamara, P.J.; Koch, J.D.; Liu, Z.; Zitomer, D.H. Pyrolysis of Dried Wastewater Biosolids Can Be Energy Positive. Water Environ. Res. 2016, 88, 804-810. [CrossRef] [PubMed]

37. Moreira, R.; Chenlo, F.; Torres, M.D. Simplified algorithm for the prediction of water sorption isotherms of fruits, vegetables and legumes based upon chemical composition. J. Food Eng. 2009, 94, 334-343. [CrossRef]

38. Hyun, C.; Burt, Z.; Crider, Y.; Nelson, K.L.; Prasad, C.S.S.; Rayasam, S.D.G.; Tarpeh, W.; Ray, I. Sanitation for Low-Income Regions: A Cross-Disciplinary Review. Annu. Rev. Environ. Resour. 2019, 44, 287-318. [CrossRef]

39. van Eekert, M.H.A.; Gibson, W.T.; Torondel, B.; Abilahi, F.; Liseki, B.; Schuman, E.; Sumpter, C.; Ensink, J.H.J. Anaerobic digestion is the dominant pathway for pit latrine decomposition and is limited by intrinsic factors. Water Sci. Technol. 2019, 79, 2242-2250. [CrossRef] [PubMed]

40. Bourgault, C.; Shaw, K.; Dorea, C. Dominant decomposition pathways in pit latrines: A. commentary. Water Sci. Technol. 2019, 80, 1392-1394. [CrossRef]

41. Niemczynowicz, J. Urban hydrology and water management-Present and future challenges. Urban Water 1999, 1, 1-14. [CrossRef]

42. Hennigs, J.; Ravndal, K.T.; Blose, T.; Toolaram, A.; Sindall, R.C.; Barrington, D.; Collins, M.; Engineer, B.; Kolios, A.J.; Adam, E.M.; et al. Field testing of a prototype mechanical dry toilet flush. Sci. Total Environ. 2019, 668, 419-431. [CrossRef]

43. Koné, D.; Cofie, O.; Zurbrügg, C.; Gallizzi, K.; Moser, D.; Drescher, S.; Strauss, M. Helminth eggs inactivation efficiency by faecal sludge dewatering and co-composting in tropical climates. Water Res. 2007, 41, 4397-4402. [CrossRef] [PubMed]

44. Naidoo, D.; Getahun, S.; Stringel, S.S. Characterization of Faecal Material Behaviour during Drying; Pollution Research Group at University of KwaZulu-Natal: Durban, South Africa, 2018.

(C) 2020 by the authors. Licensee MDPI, Basel, Switzerland. This article is an open access article distributed under the terms and conditions of the Creative Commons Attribution (CC BY) license (http://creativecommons.org/licenses/by/4.0/). 